\title{
NF1 loss disrupts Schwann cell-axonal interactions: a novel role for semaphorin $4 \mathrm{~F}$
}

\author{
Simona Parrinello, ${ }^{1,5}$ Luke A. Noon, ${ }^{1,5}$ Marie C. Harrisingh, ${ }^{2}$ Patrick Wingfield Digby, ${ }^{1}$ \\ Laura H. Rosenberg, ${ }^{1}$ Catherine A. Cremona, ${ }^{1}$ Pedro Echave, ${ }^{1}$ Adrienne M. Flanagan, ${ }^{3}$ \\ Luis F. Parada, ${ }^{4}$ and Alison C. Lloyd ${ }^{1,6}$ \\ ${ }^{1}$ MRC Laboratory for Molecular Cell Biology, Department of Cell and Developmental Biology and the UCL Cancer \\ Institute, University College London, London WC1E 6BT, United Kingdom; ${ }^{2}$ Department of Cellular and Molecular \\ Physiology, Yale School of Medicine, New Haven, Connecticut 06520, USA; ${ }^{3}$ Institute of Orthopaedic and Musculoskeletal \\ Science, UCL, Royal National Orthopaedic Hospital, Middlesex HA7 4LP, United Kingdom; ${ }^{4}$ Department of Developmental \\ Biology and Kent Waldrep Foundation Center for Basic Research on Nerve Growth and Regeneration, University of Texas \\ Southwestern Medical Center, Dallas, Texas 75390, USA
}

Neurofibromatosis type 1 (NF1) patients develop neurofibromas, tumors of Schwann cell origin, as a result of loss of the Ras-GAP neurofibromin. In normal nerves, Schwann cells are found tightly associated with axons, while loss of axonal contact is a frequent and important early event in neurofibroma development. However, the molecular basis of this physical interaction or how it is disrupted in cancer remains unclear. Here we show that loss of neurofibromin in Schwann cells is sufficient to disrupt Schwann cell/axonal interactions via up-regulation of the Ras/Raf/ERK signaling pathway. Importantly, we identify down-regulation of semaphorin 4F (Sema4F) as the molecular mechanism responsible for the Ras-mediated loss of interactions. In heterotypic cocultures, Sema4F knockdown induced Schwann cell proliferation by relieving axonal contact-inhibitory signals, providing a mechanism through which loss of axonal contact contributes to tumorigenesis. Importantly, Sema4F levels were strongly reduced in a panel of human neurofibromas, confirming the relevance of these findings to the human disease. This work identifies a novel role for the guidance-molecules semaphorins in the mediation of Schwann cell/axonal interactions, and provides a molecular mechanism by which heterotypic cell-cell contacts control cell proliferation and suppress tumorigenesis. Finally, it provides a new approach for the development of therapies for NF1.

[Keywords: NF1; Ras; Schwann cell/axonal interactions; heterotypic; semaphorins; tumorigenesis]

Supplemental material is available at http://www.genesdev.org.

Received June 3, 2008; revised version accepted September 30, 2008.

Neurofibromatosis type 1 (NF1) is a common autosomal dominant genetic disorder of the nervous system that affects one in 3500 people worldwide (Rubin and Gutmann 2005). NF1 patients are heterozygous for loss of function mutations in the NF1 tumor suppressor gene. The most distinctive clinical manifestation of the disease is the development of multiple neurofibromas. These are highly heterotypic benign tumors of the peripheral nerve sheath mainly composed of Schwann cells, fibroblasts, perineurial, inflammatory, and vascular cells embedded in a rich extracellular matrix (Riccardi 1992). Despite the heterogeneity of neurofibromas, it is known that Schwann cells are the neoplastic cell type in these tumors and the limiting step in their trans-

\footnotetext{
${ }^{5}$ These authors contributed equally to this work. ${ }^{6}$ Corresponding author.

E MAIL alison.1loyd@ucl.ac.uk; FAX 44-207-679-7805.

Article is online at http://www.genesdev.org/cgi/doi/10.1101/gad.490608.
}

formation is loss of the second NF1 allele /Colman et al. 1995; Serra et al. 2000; Zhu et al. 2002; Rubin and Gutmann 2005). Neurofibromas are divided into two subtypes called dermal and plexiform. The former affect single terminal nerves and tend to be small and circumscribed, whereas the latter develop within multiple fascicles of deep primary nerves and are usually extensive and diffuse. Although benign in nature, neurofibromas cause severe pain, disfigurement, and neurological defects. Additionally, while dermal neurofibromas have no lifetime risk of malignant transformation, plexiform neurofibromas can progress to highly aggressive sarcomas called malignant peripheral nerve sheath tumors (MPNST) that are almost invariably lethal (Friedman and Birch 1997).

The NF1 gene encodes the large cytoplasmic protein neurofibromin (NF1) that contains a Ras GTPase-activating protein (GAP) domain. GAPs accelerate the conversion of active GTP-bound Ras to its inactive GDP-bound 
form, thereby inactivating Ras signaling. Thus, loss of neurofibromin results in hyperactivation of Ras and its downstream effectors (Cichowski and Jacks 2001). Elevated levels of active Ras have been detected in $\mathrm{NF}^{-/-}$ and MPNST-derived Schwann cells and shown to be critical for the maintenance of a transformed phenotype in these cells (Basu et al. 1992; DeClue et al. 1992; Kim et al. 1995). However, little is known about how Ras hyperactivation might affect Schwann cell behavior or contribute to their transformation.

Schwann cells are the glial cells that wrap and myelinate axons in the peripheral nervous system (Jessen and Mirsky 2005). The behavior of Schwann cells is strictly under the control of axonal signals both during development and in adulthood. Signals from axons regulate Schwann cell/axonal interactions, provide proliferative and survival signals, and direct the polarization and differentiation programs to either nonmyelinating or myelinating phenotypes (Corfas et al. 2004; Michailov et al. 2004; Taveggia et al. 2005; Chan et al. 2006). Moreover, in the adult, signals from damaged axons can drive a tightly controlled regenerative program to produce new Schwann cells to aid nerve repair. In this process, Schwann cells dedifferentiate to a more progenitor-like cell type, proliferate dissociated from axons and then redifferentiate as part of the repair process (Scherer and Salzar 2001). Interestingly, it appears that these strict controls have gone awry in neurofibromas, in that tumors are composed of progenitor-like Schwann cells that have lost the ability to interact with axons and proliferate abnormally (Zhu et al. 2002; Corfas et al. 2004; Harrisingh and Lloyd 2004; Rubin and Gutmann 2005).

Importantly, the pathology of neurofibromas and recent mouse models have shown that loss of normal axonal contact is a critical early event in tumor formation, but the mechanisms responsible are still unknown (Joseph et al. 2008; Wu et al. 2008; Zheng et al. 2008). Here we show that NF1 loss via Ras/Raf/ERK signaling impairs the ability of Schwann cells to associate with axons and induce preassociated Schwann cells to dissociate from axons in primary coculture systems. We identify down-regulation of the guidance molecule semaphorin 4F (Sema4F) as the molecular mechanism through which normal Schwann cell/axonal interactions are disrupted upon Ras hyperactivation. Furthermore, we show that down-regulation of Sema4F in Schwann cell/axonal cocultures results in Schwann cell proliferation, a hallmark of tumorigenesis. Importantly, we find that Sema4F expression is strongly down-regulated in a panel of human neurofibromas and in MPNST-derived Schwann cell tumor lines isolated from NF1 patients. Together, our results identify a novel role for a semaphorin, mediating Schwann/cell axonal interactions, and provide a new molecular mechanism of neurofibroma formation.

\section{Results}

In normal nerves, Schwann cells are exclusively found associated with axons, whereas the majority of Schwann cells within neurofibromas have lost axonal contact. To understand whether this behavior is triggered by Ras hyperactivation resulting from NF1 loss, we established a defined coculture system of primary rat postnatal dorsal root ganglion neurons (DRGs) and Schwann cells that recapitulates their normal interactions in the peripheral nervous system (Wood and Bunge 1975; Kim et al. 1995). As observed in time-lapse experiments, when normal Schwann cells are added to DRGs, cell processes make contact with axons, associate and align to them, and eventually proliferate in response to axonal signals. Importantly, once established, association is tightly maintained despite extensive remodelling of the axonal network by the Schwann cells (Supplemental Movie S1). To mimic elevated Ras signaling that results from loss of neurofibromin, we infected early passage rat Schwann cells (NS) with a retrovirus that coexpresses oncogenic RasV12 and GFP (NS-RasV12). Control cells were infected with GFPexpressing empty vector (NS-Ctl). As expected, NSRasV12 cells, but not NS-Ctl cells, rapidly acquired a refractile morphology typical of Ras transformed cells. Twenty-four hours post-infection, NS-Ctl and NS-RasV12 cells were seeded onto normal rat DRGs and the interaction of GFP-labeled cells with axons studied using time-lapse microscopy (Supplemental Movies S2, S3). Whereas the behavior of NS-Ctl cells was indistinguishable from uninfected cells, we observed a striking phenotype in NS-RasV12 cocultures. As in control cultures, NS-RasV12 cells extended lamellipodia to establish axonal contacts. However, once in contact with axons, NSRasV12 Schwann cells failed to align and associate tightly to them. Rather, for most cells, the interaction appeared transient and Schwann cells often dissociated from an axon and moved to a different axon to initiate another cycle of loose interaction. We quantified the disruption to the axonal interactions on fixed cocultures. Seven hours to $8 \mathrm{~h}$ after seeding NS-Ctl or NS-RasV12 cells onto DRGs, the cocultures were fixed and axons stained for the neurofilament marker RT97. GFP-positive cells were then categorized on the basis of their position in relation to axons. We detected three types of Schwann cell behavior: (1) cells that were fully associated with axons and displayed tightly aligned cytoplasm and nucleus to axonal processes in a parallel manner (associated); (2) cells that made multiple cytoplasmic contacts with axons but failed to align their cell bodies and/or nuclei to them (associated but not aligned); (3) cells that completely lacked axonal contact despite being in close proximity to axons (nonassociated). For additional details of the scoring method see Supplemental Figure S1A. As shown in Figure 1, A and B, whereas the vast majority of Schwann cells in control cultures associated normally to DRGs, $\sim 50 \%$ of NS-RasV12 Schwann cells displayed aberrant axonal interaction, with a marked increase in both categories. Thus, oncogenic Ras signaling in normal Schwann cells is sufficient to disrupt their association with axons.

To determine whether Ras impairs Schwann cell/axonal association through the canonical Raf/ERK signaling pathway, we used primary rat Schwann cells infected with a 
A

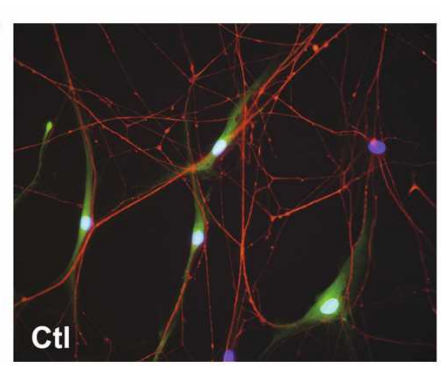

C

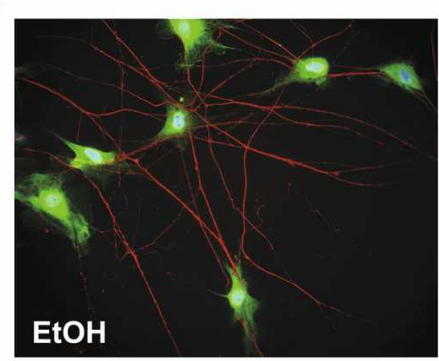

E

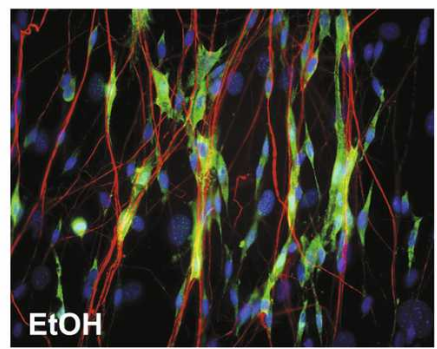

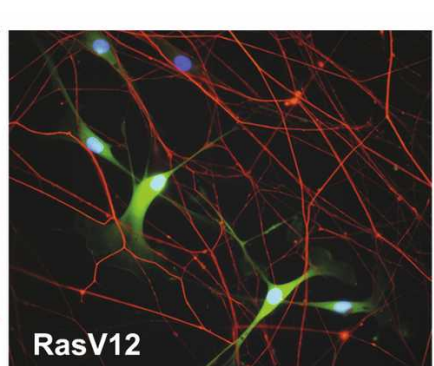
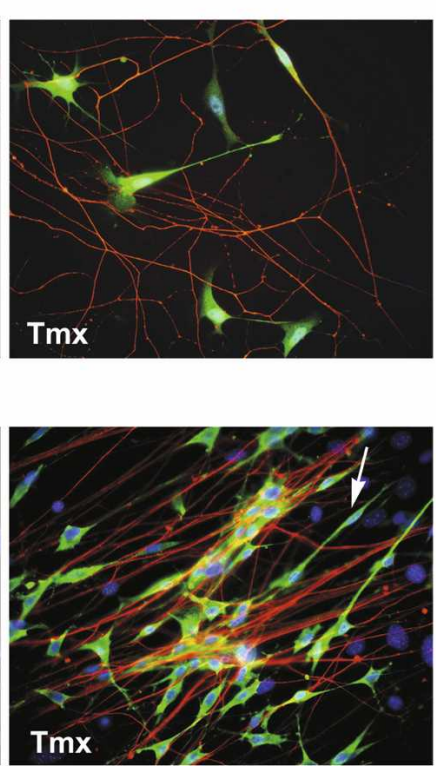

B

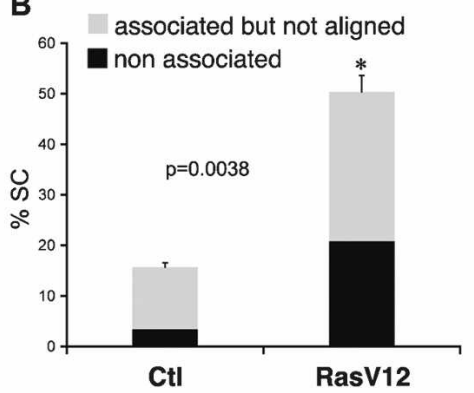

D

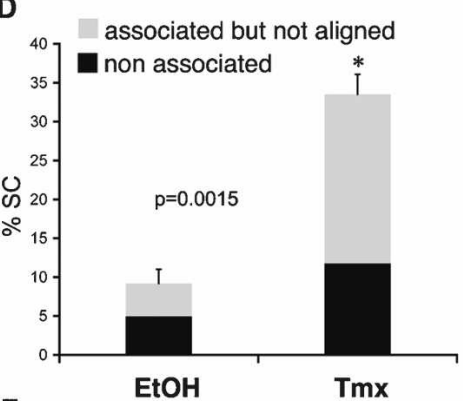

$\mathbf{F}$

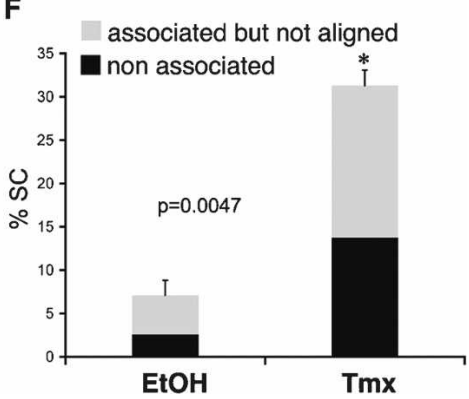

Figure 1. Oncogenic Ras/Raf impairs Schwann cell-axonal interactions. $(A-D)$ Primary rat DRG-Schwann cells association assays. $(E, F)$ Primary rat DRG-Fibroblast-Schwann cell dissociation assay. (A) Immunofluorescence staining for neurofilament marker RT97 (red) and GFP (green) of NS-Ctl (Ctl) or NS-RasV12 (RasV12) infected Schwann cells. Nuclei are counterstained with Hoechst. (C,E) Immunofluorescence staining for RT97 (red) and Schwann cell marker S100 (green) of NS $\Delta$ RafER cocultured with DRGs (C) or DRG and fibroblasts $(E)$ in the presence of vehicle $(\mathrm{EtOH})$ or tamoxifen $(\mathrm{Tmx})$. Arrow in $E$ indicates an example of a dissociated Schwann cell. $(B, D, F)$ Quantification of Schwann cell-axonal interactions. Graphs show the percentage of Schwann cells in the cultures that fail to associate (black) or associate but do not align (gray) with axons. Data represent mean \pm SE of duplicate cultures $(n>400$ cells; asterisk indicates statistical significance and $P$ values are shown). For each data set, a representative experiment of three independent repeats that gave similar results is shown.

retrovirus encoding an inducible Raf protein(NS $\Delta$ RafER). In this system the Raf-1 kinase domain ( $\Delta$ Raf) is fused to the estrogen receptor hormone-binding domain (ER) (Lloyd et al. 1997) so that Raf kinase is inactive in the absence of a ligand, but can be rapidly activated upon addition of the estrogen homolog tamoxifen (Tmx) resulting in sustained ERK activation (Samuels et al. 1993). We pretreated NS $\Delta$ RafER cells with either vehicle (EtOH) or Tmx for $24 \mathrm{~h}$ and then seeded the cells onto DRGs. Similarly to Ras-infected cultures, addition of Tmx, but not $\mathrm{EtOH}$, resulted in the acquisition of a "Ras phenotype" with cells becoming more refractile. Cocultures were then monitored by time-lapse microscopy (Supplemental Movies S4, S5) or fixed after 7-8 h for immunofluorescence analysis and quantification (Fig. 1C, D). Unlike EtOH-treated control cells, which rapidly recognized, aligned, and associated with axons, the majority of Tmx-treated cells only made transient and loose contact with axons, failed to align and associate and frequently moved from axon to axon. Thus, activation of Raf kinase resulted in a phenotype indistinguishable from Ras-infected cells. These data indicate that oncogenic Ras impairs Schwann cell/axonal interactions via the ERK signaling pathway.

In neurofibromas, Schwann cells are found without association with axons most likely as a result of dissociation of cells that lose NF1 expression. We therefore sought to address whether Ras/Raf/ERK signaling in associated Schwann cells can also induce their dissociation from axons. To do so, we modified the coculture system described above to include primary rat perineural fibroblasts, as we found these cultures, closely mirror the organization of the peripheral nerve (Obremski et al. 1993 ) in that the Schwann cells align and associate very 
tightly with bundles of axons, making this an ideal system to detect changes in established Schwann cell-axonal interactions. We set up cocultures of DRGs, fibroblasts, and NS $\Delta$ RafER cells in defined medium. Within 3 $\mathrm{d}$, reorganization of cultures could be detected, with discrete bundling of the axons that became ensheathed by groups of Schwann cells. Fibroblasts remained under the axon-Schwann cell network and between axonal bundles. Next, we treated the cocultures with EtOH or Tmx for 24-28 h and analyzed the cultures by time-lapse microscopy and immunostaining. As shown in Supplemental Figure S1, B and C, activation of Raf kinase resulted in the dissociation of a large proportion of the Schwann cells. Immunofluorescence analysis confirmed this behavior (Fig. 1E,F). While EtOH-treated cultures displayed axon bundles ensheathed by cords of parallel Schwann cells, Tmx-treated cultures contained many Schwann cells that had lost proper alignment and/or had dissociated completely from the axons. In these cultures both groups of nonassociated and associated but not aligned cells increased dramatically in Tmx cultures compared with EtOH controls. Thus, activation of the Ras/Raf/ERK signaling pathway is sufficient to induce the dissociation of Schwann cells from axons.

Together, our results strongly suggest that elevated Ras signaling, due to loss of neurofibromin, is responsible for the disruption of Schwann cell/axonal interactions observed in neurofibromas. However, neurofibromin has also been linked to Ras-independent signaling pathways. Moreover, overexpression of oncogenic Ras/ Raf and NF1 loss might trigger different levels of ERK activation and therefore not be directly comparable. To assess whether NF1 loss interferes with Schwann cell/ axonal interactions, we took two parallel approaches. First, we used RNAi to down-regulate NF1 expression in rat Schwann cells. We transiently transfected siRNA to Nf1 into primary rat Schwann cells and confirmed the efficacy of the knockdown by quantitave RT-PCR and Western blotting (Supplemental Fig. S2B,H). Forty-eight hours post-transfection NF1 knockdown cells, but not control cells, had acquired a refractile morphology, typical of Ras-overexpressing cells (Supplemental Fig. S2A). Both cell types were seeded onto rat DRGs and analyzed by time-lapse microscopy and quantification of immunostained cultures as above. Similarly to Ras/Raf overexpression, down-regulation of NF1 in rat Schwann cells disrupted Schwann cell/axonal interactions and in fixed cultures resulted in a large increase in both groups of cells with deregulated association (Fig. 2A,B). Second, we isolated primary Schwann cells from $N f 1^{\text {flox/flox }}$ mice that carry conditional alleles at the $N f 1$ locus (Zhu et al. 2002). Recombination of the Nf1 gene was induced by infecting the cultures with adenoviruses constructed to express Cre recombinase. Control cultures were infected with the same adenoviral vectors encoding GFP. In addition, we infected wild-type primary Schwann cells with both adenoviruses to control for any Cre-mediated toxicity. Infection conditions were optimized to achieve maximal infection efficiency as judged by the percentage of GFP-positive cells (>95\%) and minimal cell death.
Recombination of the Nf1flox alleles and resultant ablation of NF1 expression was confirmed by PCR (data not shown) and Western blotting (Fig. 2H). Four-day to 6-d post-infection Schwann cells transduced with adenoGFP (GFP) or adeno-Cre (CRE) were seeded onto rat DRGs and their association scored by immunofluorescence analysis. No difference in axonal association could be detected between GFP and CRE-infected wild-type cells (Supplemental Fig. S2C,D). In contrast, as in the rat cocultures, Nf1 recombination induced a dramatic change in Schwann cell/axonal interactions compared with controls (Fig. 2C,D). Whereas, the vast majority of GFP Schwann cells made contact and aligned with axons, many CRE cells showed aberrant axonal interactions with a marked increase in nonassociated cells and a more modest increase in the associated but not aligned group. This was in contrast to rat association cultures where the majority of the Schwann cells remained associated but were not properly aligned. We think this discrepancy might be attributable to less efficient basal association of murine cells to rat axons. Nonetheless, the behavior of GFP and CRE cells on axons was markedly different. To address whether NF1 loss also triggers dissociation of Schwann cells from axons, we established orthotypic cultures of Schwann cells, neurons, and fibroblasts isolated from embryonic $N f 1^{\text {flox/flox }}$ DRGs. Within $7 \mathrm{~d}$, these cultures underwent a profound reorganization to generate axonal bundles ensheathed by Schwann cells that sat on top of a layer of fibroblasts (Fig. 2E). Importantly, the cellular organization seen in this system closely resembles the rat dissociation assay described above (Fig. 1E), and is thought to mimic peripheral nerve structure (Rosenbaum et al. 1999). Indeed, upon addition of differentiation medium, robust myelination could be achieved at this stage (data not shown). As above, Nf1flox recombination was induced using adenoviral-mediated delivery of Cre recombinase. For these experiments we optimized the culture conditions to achieve maximal infection of Schwann cells and minimal cross-infection of neurons and fibroblasts, as judged by GFP fluorescence. Strikingly, within 3-6 d from infection we observed pronounced dissociation of CRE, but not GFP, Schwann cells from axons. Thus, similarly to oncogenic Ras/Raf overexpression, NF1 loss disrupts Schwann cell/axonal interactions, most likely as a result of Ras hyperactivation (Fig. 2E,F).

To test this more directly, we repeated the $N f 1^{\text {flox/flox }}$ association studies in the presence of specific inhibitors of downstream effectors of Ras signaling. As shown in Figure 2G, the MEK inhibitor UO126, but not the PI3 Kinase inhibitor LY294002, completely abolished the association defect of CRE Schwann cells. Efficacy of the inhibitors was confirmed by Western blotting (data not shown). We conclude that in neurofibromas, loss of neurofibromin in Schwann cells induces their dissociation from axons through Ras/Raf/ERK signaling. Our data also indicate that rat NS $\triangle$ RafER cells can be used to model $N f 1^{-1-}$ Schwann cell behavior.

The molecules that mediate Schwann cell/axonal interactions are poorly defined; therefore, to address the 
A
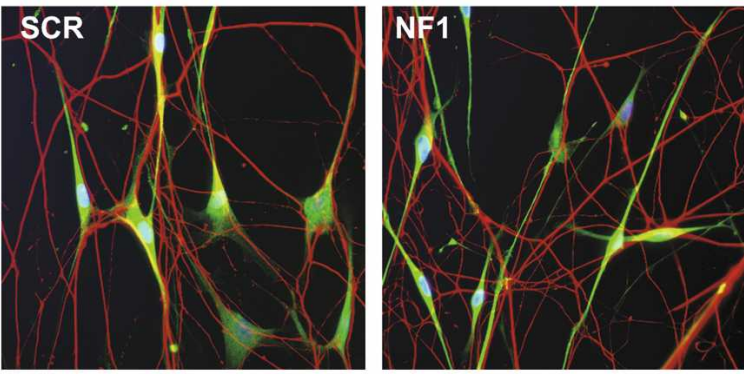

C

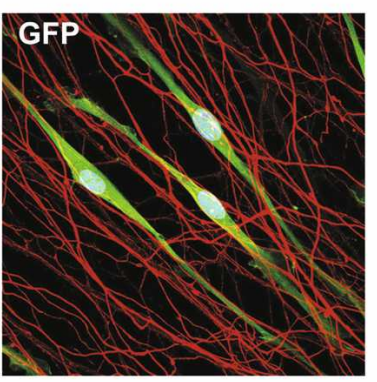

E

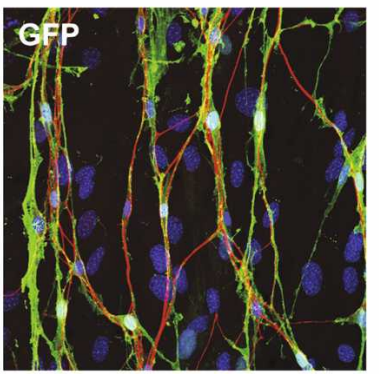

G

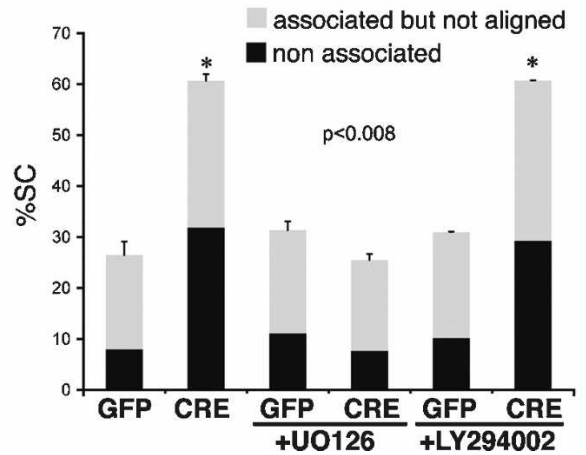

B

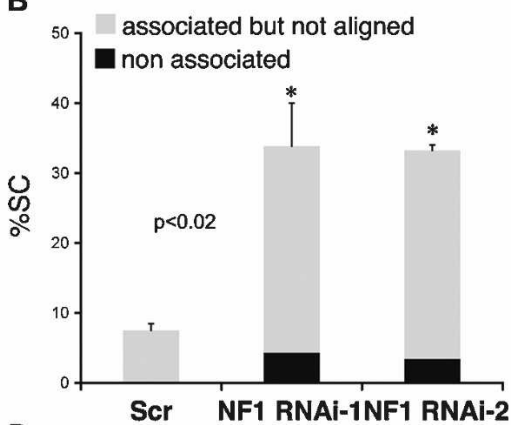

D

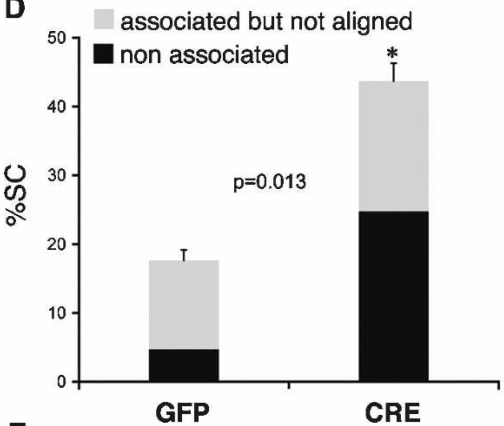

F

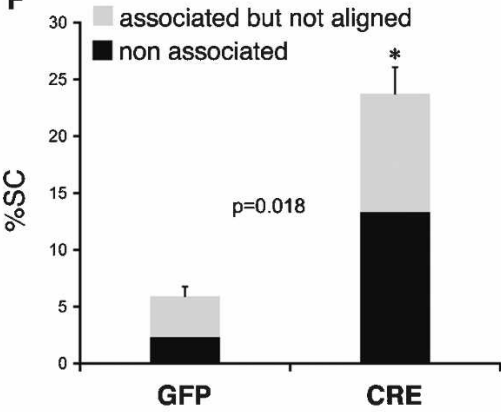

H

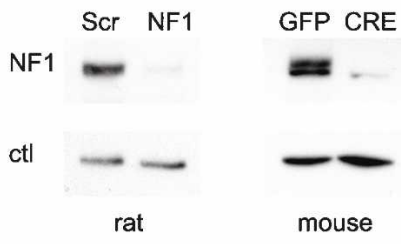

Figure 2. NF1 loss impairs Schwann cell-axonal interactions through the Raf/ERK pathway. $(A, B)$ Primary rat DRG-Schwann cells association assays. $(C, D, G)$ Primary rat DRG-Nf1 flox/flox mouse Schwann cell association assay. (E, F) Orthotypic $N f 1^{\text {flox } / f l o x} \mathrm{DRG}-$ fibroblast-Schwann cell dissociation assay. (A) Immunofluorescence staining for RT97 (red) and Schwann cell marker S100 (green) of NS cells transfected with scrambled or one of two independent siRNA oligos to NF1 cocultured with DRGs. Nuclei are counterstained with Hoechst. (C,E) Immunofluorescence staining for Schwann cell marker p $75^{\text {NGFR }}$ (green) and RT97 (red) of Adeno-GFP-infected (GFP) or Adeno-Cre-infected (CRE) cultures. $(B, D, F)$ Quantification of Schwann cell/axonal interactions. Shown is one representative experiment of three that gave similar results. Bars represent mean \pm SE of duplicate cultures $(n>400$ cells $)$. Asterisk indicates statistical significance as shown by $P$ value. $(G)$ Quantification of DRG-Nf1 flox/flox Schwann cells association assays performed in the absence (left GFP and CRE bars) or presence (middle and right GFP and CRE bars) of specific inhibitors of Ras signaling (U0126 $15 \mu M$, LY294002 $20 \mu \mathrm{M}$ ). (H) Western analysis of neurofibromin (NF1) knockdown in rat NS (left) and mouse NS cells (right).

molecular mechanisms through which Ras/Raf/ERK signaling might disrupt Schwann cell/axonal interactions in NF1 we took a candidate approach. We used microar- ray analysis to identify adhesion molecules whose expression changed following Raf activation. We compared RNA of NS $\Delta$ RafER cells treated with EtOH or Tmx for 
$24 \mathrm{~h}$ in defined serum-free culture conditions. One-thousand-fifty-seven probe sets were differentially downregulated by Raf activation, of which 379 were considered to be strongly down-regulated (>-3.5-fold). We selected six strongly down-regulated candidates based on their known function and cell surface expression (none of the up-regulated genes were considered good candidates). We validated the microarray results by quantitative RT-PCR in one independent set of EtOH- and Tmxtreated NS $\triangle$ RafER cultures and two independent sets of GFP- and CRE-infected murine $N f 1^{\text {flox/flox }}$ Schwann cells (Supplemental Fig. S3A). We reasoned that molecules down-regulated in both systems would be likely mediators of the Ras-induced phenotype. Of the six candidates, only four (Semaphorin 4F, $\alpha$ catenin-like 1, cadherin 13, and protocadherin 20) were significantly down-regulated upon NF1 loss (Fig. 3A) and Raf activation (Supplemental Fig. S3A).

To test whether the down-regulation of any of these genes was responsible for the Ras-induced disruption of Schwann cell/axonal interactions, we used RNAi to specifically down-regulate their expression. siRNA oligos for each of the genes tested were transfected into normal rat Schwann cells (NS) and efficacy of the knockdown confirmed by quantitative RT-PCR (Supplemental Fig. S3B). Thirty-six-hour post-transfection NS cells were seeded onto rat DRGs and 7-8 h later cultures were fixed and quantified. Down-regulation of cadherin 13, protocadherin 20, or $\alpha$-catenin-like 1 did not affect Schwann cell association to axons, suggesting that these molecules are not involved in normal Schwann cell/axonal interactions and do not mediate the Ras phenotype. In contrast, knockdown of semaphorin 4F (Sema4F) dramatically disrupted axonal association and alignment of NS (Fig. 3B,C). Strikingly, the effect of Sema4F siRNA closely mirrored the disregulation of Schwann cell/axonal interactions observed in Ras/Raf cocultures (Fig. 1). To rule out off-target effects, we repeated the same assay using two independent siRNA oligos (Fig. 3D) and found comparable disruption of Schwann cell/axonal association. Moreover, using site-directed mutagenesis, we generated an RNAi-resistant form of Sema4F (Sema4F*) and confirmed resistance to RNAi knockdown by quantitative RT-PCR (data not shown). Importantly, transient transfection of NS cells with Sema4F* prior to Sema4F knockdown, fully rescued the association defect, confirming the specificity of the Sema4F phenotype (Supplemental Fig. S3C). Finally, quantitative RT-PCR showed that expression levels of other semaphorins present in Schwann cells remain unchanged upon transfection with Sema4F siRNA (Fig. 3E).

Our data suggest that NF1 loss disrupts Schwann cell/ axonal interactions through Ras/Raf/ERK-mediated Sema4F down-regulation. To confirm this we measured Sema4F levels in rat Schwann cells upon siRNA-mediated NF1 down-regulation. As shown in Supplemental Figure S4A, we detected a decrease in Sema4F levels comparable with that observed in the NS $\Delta$ RafER and $N f 1^{\text {flox/flox }}$ systems. Importantly, Sema4F down-regulation could be reverted by a MEK, but not a PI3K, mTOR, or PKA inhibitor or a PKA activator (Supplemental Fig. $\mathrm{S} 4 \mathrm{~B})$, clearly demonstrating that the down-regulation is mediated by the MEK pathway and is independent of other signaling pathways reported to be downstream from loss of NF1. To confirm the role of MEK, we measured Sema4F RNA levels in NS $\Delta$ RafER cells following Raf activation in the presence or absence of two highly specific MEK inhibitors UO126 and PD184352 (Bain et al. 2007). As shown in Supplemental Figure S4C, both inhibitors completely blocked Raf-mediated Sema4F down-regulation. Additionally, we infected NS cells with either control $(\mathrm{Ctl})$ retroviruses or retroviruses carrying oncogenic Ras (RasV12) or a constitutively active form of MEK (MEK-CA) (Cowley et al. 1994) and, after drug selection, measured Sema4F levels in the cultures by quantitative RT-PCR (Supplemental Fig. S4E). As expected, both RasV12 and MEK-CA overexpression dramatically reduced Sema4F levels.

We showed that loss of semaphorin 4F is sufficient to disrupt Schwann cell/axonal interactions. To address whether it is solely responsible for the NF1-mediated disruption we asked whether overexpression of Sema4F in Schwann cells would be sufficient to rescue the disruption of axonal association triggered by NF1 loss. We transiently transfected NS with control vector alone (Ctl) or vector encoding full-length rat Sema4F. Both cell types were cotransfected with a vector encoding GFP to label transfected cells and expression was confirmed using RT-PCR (data not shown). The next day RNAi was performed using either Scr or NF1 oligos and $36 \mathrm{~h}$ later cells were seeded onto DRGs and GFP-positive cells scored. As expected, both Ctl and Sema4F cells transfected with Scr siRNA associated normally with axons, whereas NF1 loss in Ctl cells (Ctl NF1) impaired Schwann cell/axonal interactions. In striking contrast, the association defect resulting from NF1 loss was largely rescued in Sema4F cells (Sema4F NF1) (Fig. 3F). Similar results were obtained in NS $\triangle$ RafER using the same strategy (Supplemental Fig. S5) Thus, our data strongly indicate that NF1 loss disrupts Schwann cell/ axonal interactions through specific Ras/Raf/ERK-mediated down-regulation of Sema4F. They also show that Sema4F is an important mediator of the association of normal Schwann cells to axons in the peripheral nerve.

Although little is known about Sema4F, expression studies of this putative membrane-bound member of the semaphorin family, have detected expression postnatally in many tissues with highest levels in the brain (Encinas et al. 1999), suggesting that it may play an important role in the maintenance of adult nervous tissue. Our results indicate that Sema4F might also be critical in the adult peripheral nerve. To address Sema4F expression in vivo in the peripheral nerve, we extracted total RNA from sciatic nerves isolated from postnatal day $0,7,14,21$, and 60 (P0, P7, P14, P21, and P60) rats and performed quantitative RT-PCR. As shown in Supplemental Figure S6A, Sema4F expression was detected at all stages. Next, we compared levels of Sema4F in P7 sciatic nerve, first passage P7 Schwann cells cultured in defined serum-free medium for $48 \mathrm{~h}$ and first passage P7 perineurial fibro- 
A

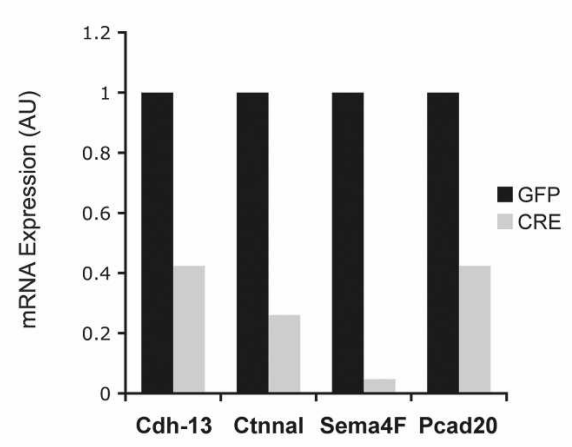

C
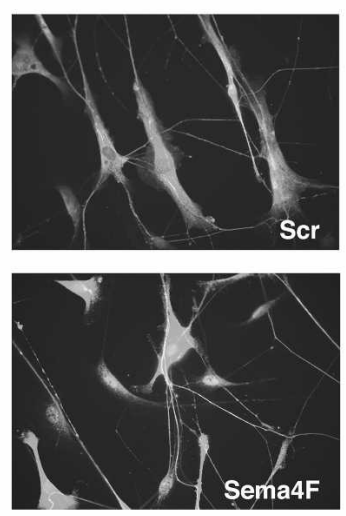

E

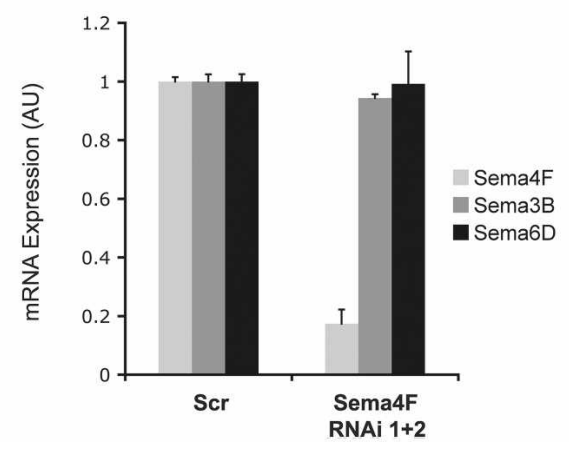

B

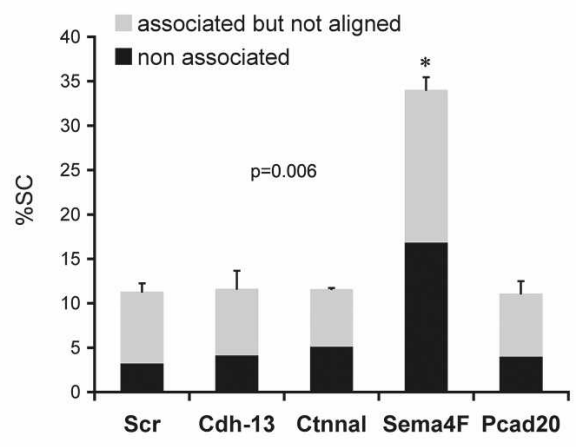

D

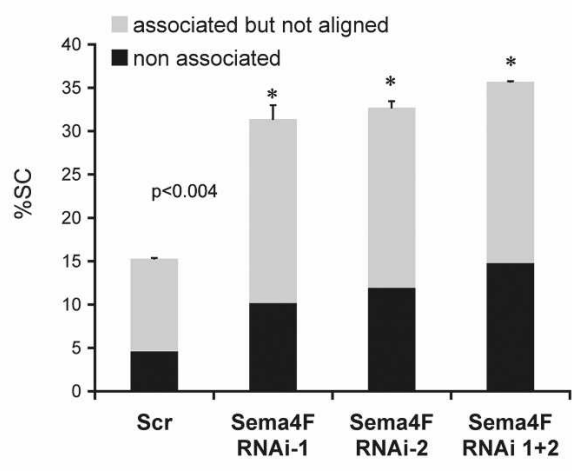

$\mathbf{F}$

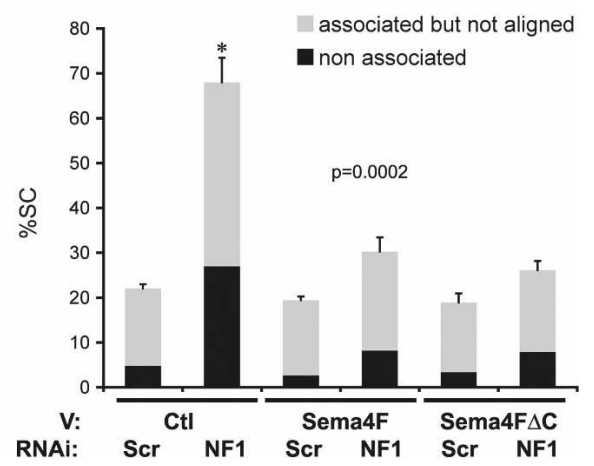

Figure 3. Down-regulation of Semaphorin 4F mediates the disruption of Schwann cell/axonal interactions induced by loss of NF1. (A) Quantitative RT-PCR analysis of mRNA expression levels of indicated proteins in purified $N f 1^{\text {flox/flox }}$ Schwann cells infected with Adeno-GFP (GFP, dark gray bars) or Adeno-Cre (CRE, light gray bars). (B) Quantification of rat DRG-Schwann cells association assay. NS were transfected with scrambled siRNA sequences (Scr) or siRNA sequences to cadherin-13 (Cdh-13), $\alpha$-catenin like 1 (Ctnnal), semaphorin 4F (Sema4F), and protocadherin 20 (Pcad20) and seeded onto DRGs. Only Sema4F siRNA disrupted axonal association. Shown is the mean \pm SE of duplicate cultures. $(n>400$ cells). Asterisk indicates statistical significance as shown by $P$ value. Data are representative of one of three independent experiments with similar results. $(C)$ Representative immunofluorescence staining of DRGs cocultured with NS cells transfected with scrambled (scr) or semaphorin 4F (Sema4F) siRNAs. Schwann cells are labeled with anti-S100 antibody and axons are labeled with anti-RT97 antibody. $(D)$ Quantification of Schwann cell-axonal interactions in DRG association assays performed with NS cells transfected with siRNA to a scrambled (scr) or two independent semaphorin 4F sequences (Sema4F RNAi-1 and -2) or their combination (Sema4F RNAi 1 + 2). (E) Quantitative RT-PCR for Schwann cell-expressed semaphorins following transfection with scrambled (scr) or semaphorin 4F (Sema4F) siRNAs. (F) Quantification of Schwann cell/axonal interactions in DRG association assays performed with NS cells cotransfected with a GFP-encoding vector and either empty vector (Ctl) or Sema4F encoding vector and subsequently transfected with either Scr or NF1 siRNA oligos as indicated. Only GFP-positive cells were scored. Shown is the mean \pm SE of triplicate cultures $(n>600$ cells $)$. Asterisks indicate statistical significance. Shown is one representative experiment of three that gave similar results.

blasts (Supplemental Fig. S6B). Sema4F levels were as high in Schwann cells as in the nerve, but almost undetectable in fibroblasts, indicating that in the postnatal nerve, where Schwann cell/axonal interactions are fully established, Schwann cells express Sema4F. This finding also confirms that Sema4F expression in cultured Schwann 
cells is not the result of prolonged tissue culture or exposure to serum, but rather reflects their phenotype in vivo. To begin to understand the function of Sema4F in the peripheral nerve, we first sought to confirm membrane localization in Schwann cells. We transiently expressed GFP-tagged Sema4F (Sema4F-GFP) or a control GFP (Ctl-GFP) vector in NS, performed subcellular fractionation and analyzed expression by Western blotting using a GFP antibody. As expected, Sema4F-GFP was only present in the membrane fraction of transfected cells. Importantly, the vast majority of GFP was detected in the cytosolic fraction, confirming successful fractionation (Supplemental Fig. S6A). Moreover, in an extracellular biotinylation assay, this fusion protein could be labeled with biotin, confirming plasma-membrane localization (data not shown). We then asked whether Sema4F in the Schwann cell plasma membrane localizes to sites of axonal contact in cocultures. We cocultured NS cells, transfected with Sema4F-GFP, with rat DRGs for $24 \mathrm{~h}$ to allow complete association and alignment and performed immunofluorescence analysis. As shown in Supplemental Figure S6B, we detected lines of GFP fluorescence that localized alongside axons in most Schwann cells. These results suggest an adhesive role for Sema4F in Schwann cell/axonal interactions. However, transmembrane semaphorins, with intracellular domains, have been purported to reverse signal into the expressing cell. Sema4F contains a relatively large intracellular region containing a PDZ-binding domain (Kruger et al. 2005). To address whether reverse signaling through Sema4F is involved in meditating Schwann cell/axonal interactions, we generated a truncated form of Sema4F lacking the entire intracellular domain (Sema4F $\Delta \mathrm{C})$ and asked whether overexpression of Sema4F $\Delta \mathrm{C}$ in $\mathrm{Nf1}$ knockdown Schwann cells would be sufficient to rescue the axonal association defect as described above for the full-length construct. Expression of the Sema4F $\Delta$ C construct was confirmed by quantitatice RT-PCR /data not shown). As shown in Figure $3 \mathrm{~F}$, Sema4F $\Delta \mathrm{C}$ rescued axonal association as efficiently as full-length Sema4F, indicating that reverse signaling, via the intracellular domain, is not required for Schwann cell/axonal interaction.

In adult nerves, signals from axons are proposed to maintain Schwann cells in a differentiated, quiescent state (Jessen and Mirsky 2005). Therefore, it is conceivable that disruption of Schwann cell/axonal contacts results in increased Schwann cell proliferation, which is a hallmark of tumorigenesis. To test this more directly, we cocultured rat NS and DRGs in defined medium to allow NS to associate to axons and proliferate exclusively in response to axonal signals as reported (Wood and Bunge 1975). After 5 d, once NS proliferation was mostly exhausted and cells fully occupied the axonal network, the culture medium was changed to either fresh defined medium or defined medium supplemented with serum and BrdU incorporation measured over $8 \mathrm{~h}$ the following day. As shown in Figure 4A, in the absence of serum minimal proliferation of NS cells on axons was observed, as expected. In contrast, upon serum stimulation of the cocultures, NS that were not associated with axons, at the edge of the coverslip, proliferated $140 \%-$ $50 \%$ ), whereas those on axons were strongly cell cycle-
Figure 4. Down-regulation of Semaphorin $4 \mathrm{~F}$ results in Schwann cell proliferation. $(A)$ BrdU incorporation of NS cells cocultured with DRGs. BrdUpositive cells in contact with axons (on) and at the periphery of the DRG with no axonal contact (off) were counted in the absence or presence of serum as indicated. Representative of three that gave similar results. Shown is the mean \pm SE of triplicate coverslips. $(B, D)$ BrdU incorporation of NS cells transfected with siRNAs to a scrambled (Scr, black) or semaphorin 4F sequence (Sema4F, gray). Upon serum stimulation, percentage of BrdU labeling of cells in contact with axons $(B)$ and without axonal contact $(D)$ was calculated. Representative experiment of three that gave similar results. Shown is the mean \pm SE of triplicate coverslips. Shown are the results using the mixture of two siRNAs to Sema4F. Similar results were obtained with each siRNA individually. $(C)$ Representative image of results quantified in $B$. (Red) axons; (green) BrdU incorporation; (blue) Hoechst.
A

NS proliferation on Axons

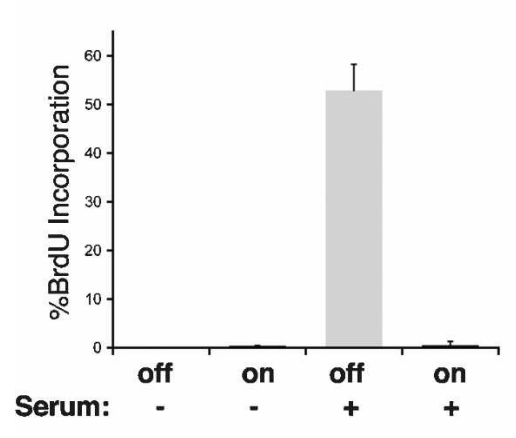

C

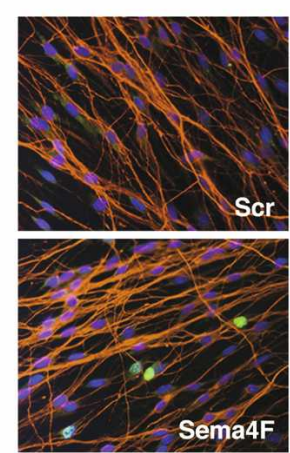

B

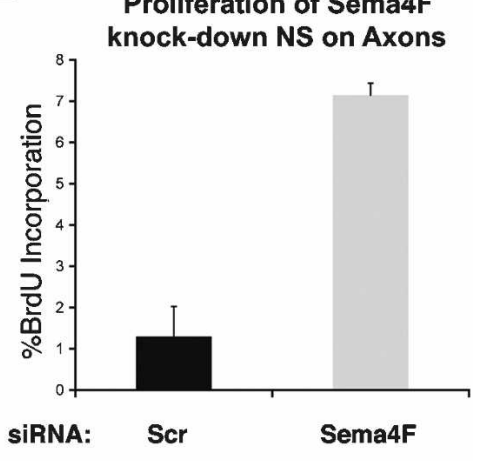

D

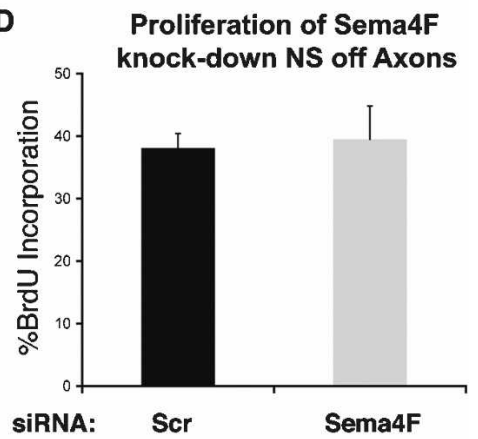


inhibited $(\sim 1 \%)$. Importantly, this effect was not dependent on cell density, as parallel NS cultures at similar high density, in the absence of axons, were able to re-enter the cell cycle upon serum addition (data not shown). These results suggest that once Schwann cell/axonal interactions are fully established, axonal signals maintain Schwann cells in a quiescent state in which they are resistant to environmental mitogenic cues. We then asked whether Sema4F down-regulation might increase Schwann cell proliferation. We seeded NS cells onto axons as above and $4 \mathrm{~d}$ later transfected the cultures with scrambled siRNA oligos (Scr) or two independent oligos to Sema4F used either separately or in combination. Strikingly, in all cases Sema4F down-regulation resulted in a sixfold to sevenfold increase in BrdU labeling of cells on axons, following serum addition (Fig. 4B,C; data not shown). Importantly, no difference in proliferation could be detected between Scr and Sema4F cells that were not in contact with axons, confirming that the effect on Schwann cell proliferation is indirect (Fig. 4D). Similar results were obtained using Schwann cells engineered to constitutively express shRNAs to Sema4F, confirming that the increase in proliferation results from Schwann cell intrinsic loss of Sema4F (Supplemental Fig. S7). Thus, our results identify a novel Ras-mediated mechanistic link between NF1 loss and tumorigenesis: Sema4F down-regulation leading to loss of heterotypic contact inhibition of proliferation.

To assess how our findings relate to tumor development in humans in vivo, we obtained RNA from sections of a panel of human neurofibromas from NF1 patients, one schwannoma, and two normal nerve tissue samples, and measured Sema4F levels by quantitative RT-PCR (Fig. 5A). Remarkably, whereas Sema4F was present in normal tissue and in the schwannoma at similar levels, little to no expression was detectable in all the neurofibromas analyzed. In addition, we also tested Sema4F levels in normal early passage primary human Schwann cells and a panel of human MPNST-derived tumor cell lines of Schwann cell origin. We chose three cell lines (NF88-3, NF90-8, and ST88-14) that were shown to be devoid of functional neurofibromin and to have elevated Ras-GTP levels (Basu et al. 1992; DeClue et al. 1992). As expected, all tumor lines failed to associate and align with axons like normal human Schwann cell controls in our coculture system (Fig. 5B). However, remarkably, two of the three cell lines (NF90-8 and ST88-14) still recognized and asociated to some extent with axons, displaying the disrupted interactions of Rasoverexpressing Schwann cells. All cells were cultured under the same conditions prior to RNA purification and Sema4F levels were tested by quantitative RT-PCR. As shown in Figure 5C, we found Sema4F to be expressed in normal human Schwann cells and to be strongly downregulated in all tumor lines analyzed.

\section{Discussion}

The development and maintenance of a tissue is, by necessity, a tightly regulated process, involving cell-autono-
A

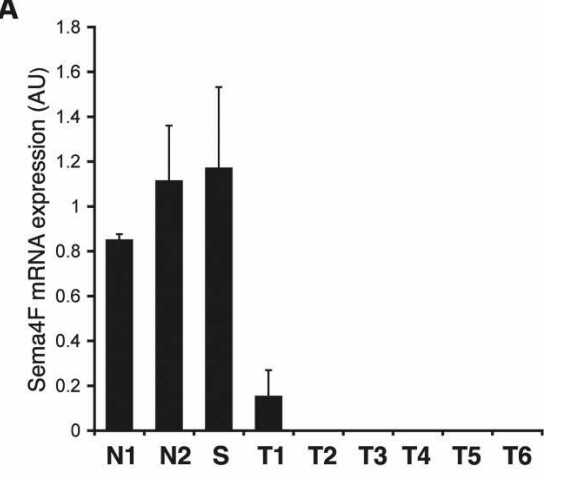

B

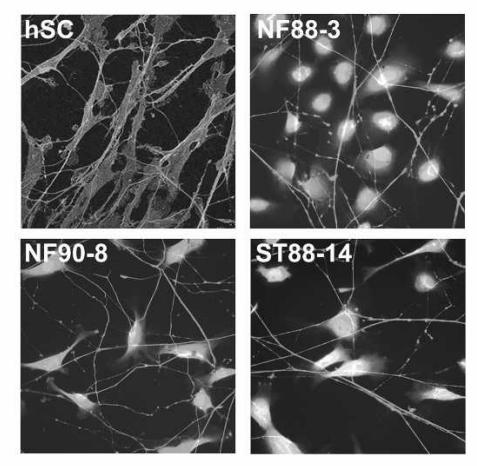

C

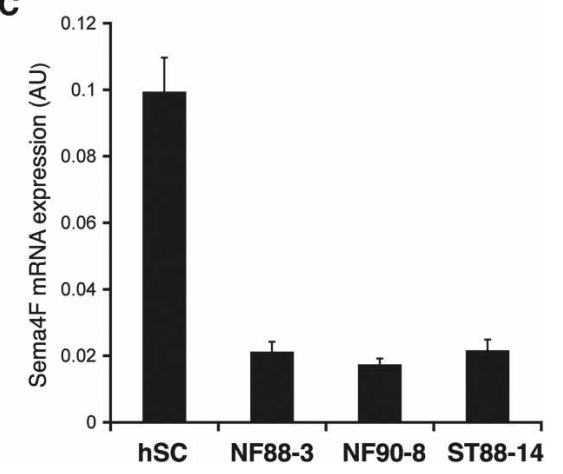

Figure 5. Semaphorin $4 \mathrm{~F}$ expression is down-regulated in human neurofibromas and MPNST-derived human tumor cell lines. $(A, C)$ Quantitative RT-PCR analysis of semaphorin 4F expression normalized to GAPDH. (A) RNA levels in sections of normal human nerve tissue (N1, N2), human schwannoma $(S)$, human dermal (T1, T2), and plexiform neurofibromas (T3-T6). (C) Expression in human Schwann cells (hSC) and three tumor cell lines (NF88-3, NF90-8, and ST88-14) of Schwann cell origin cultured under the same conditions. $(B)$ Immunofluorescence staining for neurofilament marker RT97 and $\mathrm{p} 75^{\mathrm{NGFR}}$ (hSC) or fluorescence of tumor cells prelabeled with a vital cell dye (NF88-3, NF90-8, and ST88-14).

mous controls as well as heterotypic cell signaling that ensure the correct balance and distribution of cells within a tissue. A classic example of heterotypic cell regulation is seen within peripheral nerves where survival, mitogenic, and differentiation signals, provided by axons, regulate each stage of the development of the 
Schwann cells that eventually enwrap them. In the adult, signals from the axons maintain the Schwann cells out of the cell cycle in a specialized, differentiated state that ensures the survival and efficient functioning of peripheral nerves. However, while seemingly a stable structure, the peripheral nerve is regenerative; upon injury, loss of axonal contact and signals resulting from degeneration of damaged axons, triggers Schwann cell dedifferentiation to a proliferative progenitor-like cell to promote nerve repair. Following successful axonal regrowth, signals from axons direct the redifferentiation of Schwann cells to reconstitute a fully functional nerve.

In this regard, Schwann cells are an especially interesting cell type in that a stem cell population does not persist in postnatal animals. Instead quiescent, specialized, differentiated cells, dedifferentiate, and proliferate to generate new cells. This behavior, coupled with the observation that the majority of the cells within neurofibromas have a Schwann cell phenotype, led to speculation that differentiated Schwann cells are the cell of origin of this tumor type. Recent mouse models have largely confirmed these ideas. Embryonic neural crest cells, from which Schwann cells derive, have been confirmed not to persist postnatally and Nf1 loss does not increase the persistence of these cells. Instead, these studies have implicated mature, nonmyelinating Schwann cells as the cell of origin of these tumors. (Joseph et al. 2008; Wu et al. 2008; Zheng et al. 2008). Intriguingly, it appears that the timing of the loss of $N f 1$ is important, needing to occur at a specific point during development. Whether this has relevance to the human disease is not clear and further studies are obviously required. However, consistent with the human disease, the earliest visible event in neurofibroma formation is loss of Schwann cell/axonal contacts, arguing that loss of these contacts is an important step in the etiology of the disease.

Using cell culture models that closely resemble the complex structure of peripheral nerves, we now show that increased Ras/Raf/ERK signaling is sufficient to disrupt Schwann cell-axonal interactions. Rat Schwann cells engineered to express oncogenic Ras or Raf or to down-regulate NF1 expression and recombined $N f 1^{\text {flox/flox }}$ mouse Schwann cells failed to associate and align with axons in primary coculture systems. This phenotype could be specifically reversed by treatment of $\mathrm{Nf}^{-/-}$ cells with the MEK inhibitor UO126. Moreover, acute activation of Raf kinase or loss of NF1 was sufficient to induce the dissociation of Schwann cells from axons in established primary DRG-fibroblast-Schwann cell cocultures. Importantly, our findings that ERK signaling, resulting from NF1 loss, in Schwann cells, is sufficient to induce the dissociation of Schwann cells from axons, clearly demonstrates that these results are not the result of overexpression but are relevant to neurofibroma formation, in which Schwann cells that have lost NF1 are found dissociated from axons. It is also of note that, following nerve injury, myelinating Schwann cells exhibit high levels of ERK activation for up to $3 \mathrm{~d}$ (Harrisingh et al. 2004). These levels might also be predicted to disrupt the tight alignment of Schwann cells with axons, and may be important for the normal dedifferentiation and repair process.

Our findings are in contrast however, with those of Kim et al. (1995), who reported that Ras-overexpressing and $\mathrm{NF}^{-1-}$ Schwann cells adhere normally to axons. We believe that the differences in the results can be attributed to the dynamic nature of Schwann cell/axonal interactions in these cultures. Our time-lapse experiments show that activation of Ras signaling does not abolish the ability of Schwann cells to recognize axons altogether. Rather, maintenance of axonal interactions and proper alignment to axons are impaired and cells frequently move from axon to axon. Therefore, at any given time a proportion of Schwann cells in the cocultures are found associated to axons, and could give misleading results in fixed cultures.

Very little is known about how normal Schwann cell/ axonal interactions are mediated, although a number of adhesion molecules have been reported to have a role (Wanner and Wood 2002; Corfas et al. 2004; Itoh et al. 2005). Here, we identified Sema4F as a mediator of normal Schwann cell/axonal interactions and showed that down-regulation of Sema4F is a major molecular mediator of the Ras-induced disruption of this process. Semaphorins are a large family of secreted and membraneassociated proteins most commonly associated with a role in axon guidance (Kruger et al. 2005). Sema4F is a transmembrane family member whose function is poorly understood. Unlike many semaphorins, which are predominantly expressed in development, Sema4F expression is retained postnatally in many tissues, including the central nervous system (Encinas et al. 1999). The most extensively studied biological function of semaphorins is their role in guiding axons to their targets in the developing nervous system by providing repulsive signals. However, more recently, it has been reported that semaphorins can also act as axonal attractants and mediate adhesive signals in a variety of tissues, both in development and adulthood (Wong et al. 1999; Masuda et al. 2004; Kruger et al. 2005; Casazza et al. 2007). Moreover, changes in semaphorin expression in adult tissues have been linked to pathological processes, including cancer and neurodegenerative disease (Kruger et al. 2005). Here, we identified a novel postnatal function for a semaphorin-as an important mediator of axonal/glial interactions-in that its expression in Schwann cells is required for the proper association and alignment of Schwann cells to axons. Importantly, we detected Sema4F in adult peripheral nerves where Schwann cells accounted for most of Sema4F expression. This is consistent with a recent study that reported Sema4F expression in glial cells (Cohen et al. 2003). Moreover, in cultured Schwann cells, Sema4F was detected at the plasma membrane and enriched at sites of axonal contact. Interestingly, our results with the Sema4F $\Delta \mathrm{C}$ construct indicate a predominantly adhesive role for this semaphorin. However, at present, we cannot rule out that signaling into the Schwann cell through an alternate mechanisms (i.e., a coreceptor) might be required for Schwann cell/ axonal interactions, and future studies will be needed to 
address this in greater detail. Thus, we envision that in the adult peripheral nerve, Sema4F might act in concert with other known adhesion molecules (e.g., N-cadherin, L1) to mediate and stabilize Schwann cell-axonal interactions. Interestingly, glial cells have been reported both to be important for the outgrowth of axons during development and to act as cellular conduits to facilitate axonal regrowth following nerve injury. In vitro studies have also shown that glial cells are preferential substrates for axons (Wanner et al. 2006). It will be of great interest to explore the role of semaphorins in these processes.

Sema4F was strongly down-regulated upon activation of Ras, Raf kinase, and loss of NF1 (through the MEK pathway) in cultured primary Schwann cells. Moreover, down-regulation of Sema4F, to those levels, by siRNA in normal Schwann cells was sufficient to disrupt interactions with axons to a similar extent as Ras hyperactivation and restoring Sema4F levels in NF1-knockdown cells ameliorated axonal association. Intriguingly, Sema4F levels in Schwann cells appeared to be down-regulated only in response to a seemingly "pathological" ERK signal, such as that found in cancer. Hence, the more progenitor-like Schwann cells that proliferate upon removal from the nerve in culture (and are found following nerve injury in vivo), express high levels of Sema4F and associate tightly with axons despite ERK activation as a result of normal mitogenic signaling. In contrast, sustained ERK signaling as a result of oncogenic Ras signaling strongly down-regulates Sema4F levels, resulting in the dissociation of Schwann cells from axons. Currently, the physiological significance of this pathway is unknown (although it is tempting to speculate that it may have a role early in the nerve repair process when levels of ERK signaling in Schwann cells are very high). What is clear, however, is that in pathological situations that result in high levels of ERK activation, Sema4F expression is down-regulated leading to a disruption in Schwann cell/axonal interactions. Consistent with this, we found that Sema4F levels were strongly down-regulated in a panel of human neurofibromas and MPNST-derived human tumor cell lines, indicative of this process having a role in human tumor formation, resulting from Ras activation in human Schwann cells.

How might Ras/Raf/ERK-mediated down-regulation of Sema4F contribute to neurofibroma development in NF1 patients? Both in human tumors and in neurofibromas that form in mouse models, the majority of Schwann cells are found dissociated from axons, suggesting that loss of axonal contact is a critical step in the etiology of these lesions. We showed here that axonal contact is crucial for maintaining Schwann cells in a quiescent state in which they are resistant to environmental mitogenic cues. Importantly, down-regulation of Sema4F in Schwann cell-DRG cocultures, but not in Schwann cell monocultures, resulted in elevated Schwann cell proliferation. This suggests that Sema4F loss does not affect the cell cycle directly, but rather promotes proliferation indirectly by overriding heterotypic contact-inhibitory axonal signals. This disruption in the Schwann cell microenvironment is likely to promote tumorigen- esis, as it renders Schwann cells more responsive to environmental proliferative cues. Interestingly, genetic evidence in the $N f 1^{\text {flox }}$ mouse model has shown that neurofibroma development can be contingent upon exposure of $\mathrm{Nf1^{-/- }}$ Schwann cells to an $\mathrm{Nf1^{+/- }}$ tissue environment (Zhu et al. 2002). This has led to the speculation that the haploinsufficient $N f 1$ environment might foster tumorigenesis by providing factors that promote Schwann cell proliferation. Thus, we think that in neurofibroma formation, proproliferative signals from the $N f 1^{+/-}$microenvironment synergize with Ras-induced loss of axonal contact to drive the proliferation of $\mathrm{Nf1}^{-/-}$ Schwann cells.

Some of the transformed phenotypes of $\mathrm{Nf1^{-/- }}$ Schwann cells have been linked previously to increased Ras signaling, and were shown to be reversed by Ras inhibitors (Kim et al. 1997). Here, we uncovered a novel Ras-induced tumorigenic property of $N f 1^{-/-}$Schwann cells: Loss of axonal interactions and treatment of $\mathrm{Nf1}^{-/-}$ Schwann cells with the MEK inhibitor UO126 re-established normal axonal interactions. Thus, our data corroborate the idea that therapeutics aimed at reducing Ras signaling might be useful for the treatment of neurofibromas. Additionally, our findings provide novel targets and a distinct approach for the development of therapeutics for the treatment of NF1.

\section{Materials and methods}

\section{Mice and genotyping}

$\mathrm{NF} 1^{\text {flox/+ }}$ animals from Luis Parada were backcrossed to obtain homozygous NF1 $1^{\text {flox/flox }}$ transgenic animals. Genotyping and assessment of Cre-mediated recombination were performed using sensitive three-oligonucleotide primer PCR assays as described (Zhu et al. 2002). All animal work was carried out in accordance to the guidelines and regulations of the Home Office.

\section{Cell culture}

Primary rat Schwann cells and fibroblasts derived from P7 Sprague-Dawley rat sciatic nerve were isolated and subcultured as previously reported (Mathon et al. 2001). NS $\Delta$ RafER cells are as described previously (Lloyd et al. 1997). To prepare primary mouse Schwann cells, P2-P4 sciatic and brachial nerves were dissected from $N f 1^{\text {flox/flox }}$ animals, desheathed, and treated with a mixture of collagenase $(2 \mathrm{mg} / \mathrm{mL})$ and trypsin $(1.25 \mathrm{mg} / \mathrm{mL})$ for $35 \mathrm{~min}$ at $37^{\circ} \mathrm{C}$. The tissue was then gently dissociated through a plastic pipette tip, and cells were centrifuged and plated on poly-L-lysine and laminin coated dishes in DMEM containing $5 \%$ horse serum (Invitrogen) and arabinosylcytosine (Sigma) to remove contaminating fibroblasts. After $48-72 \mathrm{~h}$, culture medium was changed to growth medium consisting of G5supplemented neurobasal medium containing 3\% horse serum (Invitrogen), recombinant GGF (20 ng/mL; R\&D Systems), dbcAMP (0.1 mM; Sigma) and kanamycin/gentamycin (Sigma). Residual fibroblasts were removed by negative immunopanning on dishes coated with Thy1.1 antibodies as described previously (Mathon et al. 2001). Murine Schwann cells were subcultured up to a maximum of four times prior to coculture with DRGs (see below). 


\section{$D R G$ preparation}

For association assays and rat dissociation assays, DRGs were dissected from P0-P1 Sprague-Dawley rats and explanted on poly-L-lysine and laminin-coated coverslips in defined medium (DMEM/F12; Invitrogen) supplemented with $100 \mathrm{ng} / \mathrm{mL}$ NGF (Alamone Laboratories), Transferrin, SATO supplement, insulin (Sigma), and penicillin/streptomycin (Invitrogen). DRGs were treated with arabinosylcytosine for $48 \mathrm{~h}$ to remove endogenous glia and fibroblasts and used 24-72 h later for coculture.

\section{DRG cocultures}

For association assays, $1.5 \times 10^{4}$ Schwann cells were seeded onto DRGs in defined medium and cocultures were fixed and stained 7-8 h later. NS $\Delta$ RafER were pretreated with vehicle or tamoxifen for $24 \mathrm{~h}$ prior to association assays. For all experiments, data represent mean \pm SE of duplicate cultures, and shown is one representative experiment of three that gave similar results. For rat dissociation assays, $1.5 \times 10^{4}$ perineurial fibroblasts were first seeded onto DRGs and $24 \mathrm{~h}$ later Schwann cells were added to the cocultures as above. After $3 \mathrm{~d}$, cultures were treated with vehicle (ethanol) or tamoxifen for $27 \mathrm{~h}$, fixed, and stained. For BrdU assays, $3 \times 10^{4}$ cells were seeded onto bare DRGs in defined medium. Five days later serum was added $\mathrm{O} / \mathrm{N}$ and BrdU added for $8 \mathrm{~h}$ the following day. Cells were fixed and costained for axons and BrdU. Cells treated with siRNA were transfected on day 4 .

\section{Mouse dissociation assays}

Orthotypic cultures were established from E13 $N F 1^{\text {flox/flox }}$ DRGs as follows. Dissected DRGs were dissociated in $0.1 \%$ trypsin (Invitrogen) for $20 \mathrm{~min}$, resuspended in culture medium consisting of neurobasal medium supplemented with $10 \%$ horse serum, B27 (Invitrogen), and NGF and plated at a density of $1.5 \times 10^{4}$ cells onto poly-L-lysine and laminin coated coverslips. After 5-7 d, cultures were infected with adeno-GFP or adeno-CRE viruses and processed for immunostaining 3-6 d later.

\section{Schwann cell infections}

The Val12 mutant H-Ras cDNA in the retrovirus pinco-GFP was a kind gift of Dr. Pier Giuseppe Pelicci. Retroviral transductions of normal rat Schwann cells to generate NS-Ctl and NS-RasV12 cells were as described previously (Mitchell et al. 2003). NS-Ctl and NS-RasV12 cells were used for association assays $24 \mathrm{~h}$ post-infection. GFP and CRE-encoding adenoviruses were a kind gift of Dr. Axel Behrens. Adenoviral supernatants were prepared as described in the manufacturer's instructions (Vivapure-VivaScience) and added at a multiplicity of infection of $\sim 80$ to purified $N F 1^{\text {flox/flox }}$ Schwann cells or $N F 1^{\text {flox/flox }}$ orthotypic cultures in the appropriate growth medium supplemented with $2 \mu \mathrm{M}$ forskolin. Twenty-four hours later the adenoviral supernatant was removed, and the medium changed to fresh growth medium. Infection conditions were optimized to achieve maximal infection efficiency as judged by the percentage of GFP-positive cells ( $>95 \%$ ) and minimal cell toxicity.

\section{Immunofluorescence and Western blotting}

Cocultures were fixed with $4 \%$ formaldehyde for $25 \mathrm{~min}$, permeabilized with $95 \%$ ice-cold methanol $/ 5 \%$ acetone blocked in $3 \%$ BSA, and incubated with primary antibodies for $2 \mathrm{~h}$ followed by incubation with FITC- or Texas Red-conjugated secondary antibodies (Alexa) for $1 \mathrm{~h}$. Nuclei were counterstained with DAPI and coverslips mounted in VectaShield (Vector Laboratories). Primary antibodies were anti-RT97 (1:400; kind gift of John Woods), anti-S100 (1:400; DAKO), and anti-p $75^{\text {NGFR }}$ (1:300; Chemicon). For staining of mouse cocultures, incubation with $\mathrm{p} 75^{\mathrm{NGFR}}$ antibody was performed prior to permeabilization. For staining of NS-Ctl and NS-RasV12-DRG cocultures, permeabilization with $0.5 \%$ Triton $\mathrm{X}$ for $10 \mathrm{~min}$ instead of methanol/acetone was used to preserve endogenous GFP fluorescence of infected cells. Schwann cell-axonal interactions were quantified visually by epifluorescence microscopy. For each experimental condition a minimum of 400 cells were randomly chosen from duplicate cultures and scored according to the criteria described in the results. All scoring was performed blind. Data are expressed as mean \pm SE and $P$ values were calculated by Student $t$ test. Western blots of mouse and rat NF1 used Santa-Cruz Biotechnologies antibody sc-67 (1:500) and of GFP used Roche antibody (1:4000). Cellular fractionation was performed as reported previously (Hase et al. 2005).

\section{Quantitative real-time PCR}

Total RNA was obtained using the RNeasy Plus Minikit (Qiagen) and $1 \mu \mathrm{g}$ of RNA was then reverse transcribed with SuperScript II Reverse Transcriptase (Invitrogen). Quantitative PCR was performed using the DyNAmo SYBR Green qPCR Kit (Finnzymes) and the Opticon 2 DNA engine (MJ Research). Intron-spanning gene-specific primer pairs were designed using the Primer3 algorithm (Rozen and Skaletsky 2000) and relative expression values for each gene of interest were obtained by normalizing to GAPDH.

\section{RNAi and transfections}

siRNA duplexes were prepared according to the manufacturer's instructions (Qiagen) and specific knockdown conditions were optimized for each target gene in primary rat Schwann cells using the HiPerfect transfection reagent (Qiagen). Depending on the gene of interest, a final concentration of 1 to $5 \mathrm{nM}$ duplex was used to achieve knockdown as assessed by quantitative PCR. FuGene 6 (Roche) was used according to manufacturer's instructions for all transient transfections.

\section{Acknowledgments}

We thank Antonella Riccio and Anne Mudge for critical reading of the manuscript, Yvonne Hay at the CRUK Molecular Biology Core Facility at the Paterson Institute for the microarray analysis, Richard Mitter at CRUK Bioinformatics and BioStatistics, London Research Institute for assistance with bioinformatics, Bernadine Idowu for assistance with tumor samples, Andrew Vaughan for help with microscopy, and David Muir for advice on human Schwann cell culture. A.C.L. is a CRUK Senior Cancer Research Fellow. S.P. is the recipient of a long-term EMBO fellowship and a Royal Society D.H. fellowship. C.A.C and P.W.D. are MRC program Ph.D. students, and L.R. is a CRUKfunded Ph.D. student. This work was supported by a CRUK program grant.

\section{References}

Bain, J., Plater, L., Elliott, M., Shpiro, N., Hastie, C.J., McLauchlan, H., Klevernic, I., Arthur, J.S., Alessi, D.R., and Cohen, P. 2007. The selectivity of protein kinase inhibitors: A further update. Biochem. J. 408: 297-315.

Basu, T.N., Gutmann, D.H., Fletcher, J.A., Glover, T.W., Col- 
lins, F.S., and Downward, J. 1992. Aberrant regulation of ras proteins in malignant tumour cells from type 1 neurofibromatosis patients. Nature 356: 713-715.

Casazza, A., Fazzari, P., and Tamagnone, L. 2007. Semaphorin signals in cell adhesion and cell migration: Functional role and molecular mechanisms. Adv. Exp. Med. Biol. 600: 90108.

Chan, J.R., Jolicoeur, C., Yamauchi, J., Elliott, J., Fawcett, J.P., $\mathrm{Ng}$, B.K., and Cayouette, M. 2006. The polarity protein Par-3 directly interacts with p75NTR to regulate myelination. Science 314: 832-836.

Cichowski, K. and Jacks, T. 2001. NF1 tumor suppressor gene function: Narrowing the GAP. Cell 104: 593-604.

Cohen, R.I., Rottkamp, D.M., Maric, D., Barker, J.L., and Hudson, L.D. 2003. A role for semaphorins and neuropilins in oligodendrocyte guidance. J. Neurochem. 85: 1262-1278.

Colman, S.D., Williams, C.A., and Wallace, M.R. 1995. Benign neurofibromas in type 1 neurofibromatosis (NF1) show somatic deletions of the NF1 gene. Nat. Genet. 11: 90-92.

Corfas, G., Velardez, M.O., Ko, C.P., Ratner, N., and Peles, E. 2004. Mechanisms and roles of axon-Schwann cell interactions. J. Neurosci. 24: 9250-9260.

Cowley, S., Paterson, H., Kemp, P., and Marshall, C.J. 1994. Activation of MAP kinase kinase is necessary and sufficient for PC12 differentiation and for transformation of NIH 3T3 cells. Cell 77: 841-852.

DeClue, J.E., Papageorge, A.G., Fletcher, J.A., Diehl, S.R., Ratner, N., Vass, W.C., and Lowy, D.R. 1992. Abnormal regulation of mammalian p21ras contributes to malignant tumor growth in von Recklinghausen (type 1) neurofibromatosis. Cell 69: 265-273.

Encinas, J.A., Kikuchi, K., Chedotal, A., de Castro, F., Goodman, C.S., and Kimura, T. 1999. Cloning, expression, and genetic mapping of Sema W, a member of the semaphorin family. Proc. Nat1. Acad. Sci. 96: 2491-2496.

Friedman, J.M. and Birch, P.H. 1997. Type 1 neurofibromatosis: A descriptive analysis of the disorder in 1,728 patients. Am. J. Med. Genet. 70: 138-143.

Harrisingh, M.C. and Lloyd, A.C. 2004. Ras/Raf/ERK signalling and NF1. Cell Cycle 3: 1255-1258.

Harrisingh, M.C., Perez-Nadales, E., Parkinson, D.B., Malcolm, D.S., Mudge, A.W., and Lloyd, A.C. 2004. The Ras/Raf/ERK signalling pathway drives Schwann cell dedifferentiation. $E M B O$ J. 23: 3061-3071.

Hase, A., Saito, F., Yamada, H., Arai, K., Shimizu, T., and Matsumura, K. 2005. Characterization of glial cell line-derived neurotrophic factor family receptor $\alpha-1$ in peripheral nerve Schwann cells. J. Neurochem. 95: 537-543.

Itoh, K., Fushiki, S., Kamiguchi, H., Arnold, B., Altevogt, P., and Lemmon, V. 2005. Disrupted Schwann cell-axon interactions in peripheral nerves of mice with altered L1-integrin interactions. Mol. Cell. Neurosci. 30: 131-136.

Jessen, K.R. and Mirsky, R. 2005. The origin and development of glial cells in peripheral nerves. Nat. Rev. Neurosci. 6: 671682.

Joseph, N.M., Mosher, J.T., Buchstaller, J., Snider, P., McKeever, P.E., Lim, M., Conway, S.J., Parada, L.F., Zhu, Y., and Morrison, S.J. 2008. The loss of Nf1 transiently promotes selfrenewal but not tumorigenesis by neural crest stem cells. Cancer Cell 13: 129-140.

Kim, H.A., Rosenbaum, T., Marchionni, M.A., Ratner, N., and DeClue, J.E. 1995. Schwann cells from neurofibromin deficient mice exhibit activation of p21ras, inhibition of cell proliferation and morphological changes. Oncogene 11: 325335.

Kim, H.A., Ling, B., and Ratner, N. 1997. Nf1-deficient mouse
Schwann cells are angiogenic and invasive and can be induced to hyperproliferate: Reversion of some phenotypes by an inhibitor of farnesyl protein transferase. Mol. Cell. Biol. 17: 862-872.

Kruger, R.P., Aurandt, J., and Guan, K.L. 2005. Semaphorins command cells to move. Nat. Rev. Mol. Cell Biol. 6: 789800.

Lloyd, A.C., Obermuller, F., Staddon, S., Barth, C.F., McMahon, M., and Land, H. 1997. Cooperating oncogenes converge to regulate cyclin/cdk complexes. Genes \& Dev. 11: 663-677.

Masuda, K., Furuyama, T., Takahara, M., Fujioka, S., Kurinami, H., and Inagaki, S. 2004. Sema4D stimulates axonal outgrowth of embryonic DRG sensory neurones. Genes Cells 9: 821-829.

Mathon, N.F., Malcolm, D.S., Harrisingh, M.C., Cheng, L., and Lloyd, A.C. 2001. Lack of replicative senescence in normal rodent glia. Science 291: 872-875.

Michailov, G.V., Sereda, M.W., Brinkmann, B.G., Fischer, T.M., Haug, B., Birchmeier, C., Role, L., Lai, C., Schwab, M.H., and Nave, K.A. 2004. Axonal neuregulin-1 regulates myelin sheath thickness. Science 304: 700-703.

Mitchell, P.J., Perez-Nadales, E., Malcolm, D.S., and Lloyd, A.C. 2003. Dissecting the contribution of p16(INK4A) and the $\mathrm{Rb}$ family to the Ras transformed phenotype. Mol. Cell. Biol. 23: 2530-2542.

Obremski, V.J., Johnson, M.I., and Bunge, M.B. 1993. Fibroblasts are required for Schwann cell basal lamina deposition and ensheathment of unmyelinated sympathetic neurites in culture. J. Neurocytol. 22: 102-117.

Riccardi, V.M. 1992. Neurofibromatosis: Phenotype, natural history and pathogenesis. The John Hopkins University Press, Baltimore, MD.

Rosenbaum, T., Kim, H.A., Boissy, Y.L., Ling, B., and Ratner, N. 1999. Neurofibromin, the neurofibromatosis type 1 RasGAP, is required for appropriate $\mathrm{P} 0$ expression and myelination. Ann. N. Y. Acad. Sci. 883: 203-214.

Rozen, S. and Skaletsky, H. 2000. Primer3 on the WWW for general users and for biologist programmers. Methods Mol. Biol. 132: 365-386.

Rubin, J.B. and Gutmann, D.H. 2005. Neurofibromatosis type 1 -a model for nervous system tumour formation? Nat. Rev. Cancer 5: 557-564.

Samuels, M.L., Weber, M.J., Bishop, J.M., and McMahon, M. 1993. Conditional transformation of cells and rapid activation of the mitogen-activated protein kinase cascade by an estradiol-dependent human raf-1 protein kinase. Mol. Cell. Biol. 13: 6241-6252.

Scherer, S. and Salzar, J. L. 2001. Axon-Schwann cell interactions during peripheral nerve degeneration and regeneration. Oxford University Press, Oxford, UK.

Serra, E., Rosenbaum, T., Winner, U., Aledo, R., Ars, E., Estivill, X., Lenard, H.G., and Lazaro, C. 2000. Schwann cells harbor the somatic NF1 mutation in neurofibromas: Evidence of two different Schwann cell subpopulations. Hum. Mol. Genet. 9: 3055-3064.

Taveggia, C., Zanazzi, G., Petrylak, A., Yano, H., Rosenbluth, J., Einheber, S., Xu, X., Esper, R.M., Loeb, J.A., Shrager, P., et al. 2005. Neuregulin-1 type III determines the ensheathment fate of axons. Neuron 47: 681-694.

Wanner, I.B. and Wood, P.M. 2002. N-cadherin mediates axonaligned process growth and cell-cell interaction in rat Schwann cells. J. Neurosci. 22: 4066-4079.

Wanner, I.B., Guerra, N.K., Mahoney, J., Kumar, A., Wood, P.M., Mirsky, R., and Jessen, K.R. 2006. Role of N-cadherin in Schwann cell precursors of growing nerves. Glia 54: 439459 . 
Parrinello et al.

Wong, J.T., Wong, S.T., and O'Connor, T.P. 1999. Ectopic semaphorin-1a functions as an attractive guidance cue for developing peripheral neurons. Nat. Neurosci. 2: 798-803.

Wood, P.M. and Bunge, R.P. 1975. Evidence that sensory axons are mitogenic for Schwann cells. Nature 256: 662-664.

Wu, J., Williams, J.P., Rizvi, T.A., Kordich, J.J., Witte, D., Meijer, D., Stemmer-Rachamimov, A.O., Cancelas, J.A., and Ratner, N. 2008. Plexiform and dermal neurofibromas and pigmentation are caused by Nf1 loss in desert hedgehogexpressing cells. Cancer Cell 13: 105-116.

Zheng, H., Chang, L., Patel, N., Yang, J., Lowe, L., Burns, D.K., and Zhu, Y. 2008. Induction of abnormal proliferation by nonmyelinating schwann cells triggers neurofibroma formation. Cancer Cell 13: 117-128.

Zhu, Y., Ghosh, P., Charnay, P., Burns, D.K., and Parada, L.F. 2002. Neurofibromas in NF1: Schwann cell origin and role of tumor environment. Science 296: 920-922. 


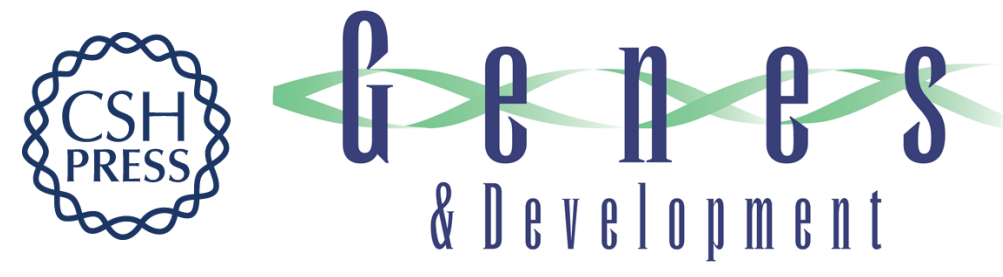

\section{NF1 loss disrupts Schwann cell-axonal interactions: a novel role for semaphorin 4F}

Simona Parrinello, Luke A. Noon, Marie C. Harrisingh, et al.

Genes Dev. 2008, 22:

Access the most recent version at doi:10.1101/gad.490608

\section{Supplemental http://genesdev.cshlp.org/content/suppl/2008/11/18/22.23.3335.DC2 Material}

References This article cites 40 articles, 13 of which can be accessed free at: http://genesdev.cshlp.org/content/22/23/3335.full.html\#ref-list-1

\section{License}

Email Alerting

Receive free email alerts when new articles cite this article - sign up in the box at the top Service 